\title{
Creation and analysis of enzymatically active micrometer protein-
}

\section{capsules}

Kai Melvin Schakowski ${ }^{\mathrm{a}^{*}}$, Christian Elm ${ }^{\mathrm{a}}$, Jürgen Linders ${ }^{\mathrm{b}, \mathrm{c}}$, Michael Kirsch ${ }^{\mathrm{a}}$

${ }^{a}$ Institute of Physiological Chemistry, University of Duisburg-Essen, University Hospital Essen, Hufelandstraße 55, 45147 Essen, Germany

${ }^{b}$ Department of Physical Chemistry, University of Duisburg-Essen, Universitätsstraße 5, 45141 Essen, Germany

${ }^{c}$ Center for Nanointegration Duisburg-Essen (CeNIDE), University of Duisburg-Essen, Carl-Benz-Straße 199, 47057 Duisburg, Germany

*Corresponding Author, kai.schakowski@uk-essen.de

Keywords: catalase, albumin, oxygen, microencapsulation, microcapsules, enzymes 


\begin{abstract}
This work describes a general method for the encapsulation of enzymes with albumin as wall material and the enzyme catalase as prime example. Care was taken for the preparation of biochemically active sub-micrometer particles in order to prevent oxygen toxicity induced by artificial oxygen carriers of any type. In cell culture experiments, capsules containing catalase did not exhibit any harmful activities in the absence of peroxides. In the presence of hydrogen peroxide application of low and medium dosed capsules below 0.05 vol\% (final concentration $0.001 \mathrm{vol} \%$ ) even increased the cell damaging process. However, a higher dosage of capsules (> $0.05 \mathrm{vol} \%$ ) prevented completely cellular disruption induced by $5 \mathrm{mM}$ hydrogen peroxide and decreased up to $90 \%$ of cellular damage at higher peroxide concentrations. These results demonstrated that encapsulated catalase was enzymatically active and the over-all activity of prepared catalase capsules was determined to be $>1000 \mathrm{U} \cdot \mathrm{mL}^{-1} \cdot \operatorname{vol} \%^{-1}$.
\end{abstract}

\title{
1 Introduction
}

In order to counteract the rising shortness on blood donations all over the world, the development of artificial blood substitutes has been investigated with several different approaches (Müller et al. 2015, Chung et al. 2016, Ellingson et al. 2017). Possible blood substitutes were created using either hemoglobine-based oxygen carriers (HbOCs) (Xiong et al. 2012, Schakowski et al. 2020) or perfluorocarbon-based oxygen carriers (PFCOCs) (Wrobeln et al. 2017). HbOCs as well as PFCOCs come with a shell of either biodegradable polymers or albumin (Chang and Yu 1995, Bauer et al. 2010, Xiong et al. 2012) whereas free hemoglobin has widely been ruled out due to nephrotoxicity (Simoni et al. 1997).

Promisingly, all these approaches have the drawback, that more intracellular components, e.g. enzymes or co-factors, are needed for the adequate replacement of red blood cells (RBCs). In order to reduce damage induced by free radicals, RBCs naturally contain various additional enzymes, such as catalase and superoxide dismutase. In 1984 TURRENS has shown that encapsulation of RBC-enzymes into liposomes is principally possible (Turrens et al. 1984). In this work we prove that the encapsulation of RBC-enzymes is possible with the more modern method of encapsulation into a shell of albumin. We take advantage of organic, inorganic and physical chemistry for the preparation of biochemically active sub-micrometer particles to prevent oxygen toxicity induced by artificial oxygen carriers of any type.

In 1913 HEARD already proposed a coherence between metal cations, carbonates and the precipitation of proteins (Heard 1913). In this work, the co-precipitation of catalase together with the hardly soluble $\mathrm{MnCO}_{3}$ template was used according to a protocol introduced by 
JOHNSON (Johnson 1982). The subsequent addition of BSA to these $\mathrm{MnCO}_{3}$-catalase generated an albumin wall thus leading to particles consisting of a $\mathrm{MnCO}_{3}$-catalase core and a BSA shell.

\section{Experimental}

\subsection{Materials}

Bovine serum albumin fraction $\mathrm{V}$ (BSA), Manganese(II) chloride tetrahydrate, Ethylenediaminetetraacetic acid disodium salt dihydrate ( $\mathrm{Na}_{2}$ EDTA) and Triton $\mathrm{X}-100$ were purchased from Sigma-Aldrich (Darmstadt, Germany); Sodium carbonate anhydrous and Sodium hydroxide were purchased from Merck (Darmstadt, Germany); Disodium phosphate dehydrate was purchased from Carl Roth (Karlsruhe, Germany); Ringer's solution was purchased from Fresenius Kabi (Bad Homburg, Germany); Gibco Minimum Essential Medium (MEM), Gibco Fetal bovine serum (FBS), Gibco Pen Strep and Gibco 0.05\% Trypsin-EDTA were purchased from Thermo Fisher Scientific (Schwerte, Germany); Catalase from bovine liver was purchased from SERVA (Heidelberg, Germany); Genipin was purchased from TCI Chemicals (Eschborn, Germany). All materials were of highest quality available.

\subsection{Synthesis of Albumin-Catalase capsules (ACCs)}

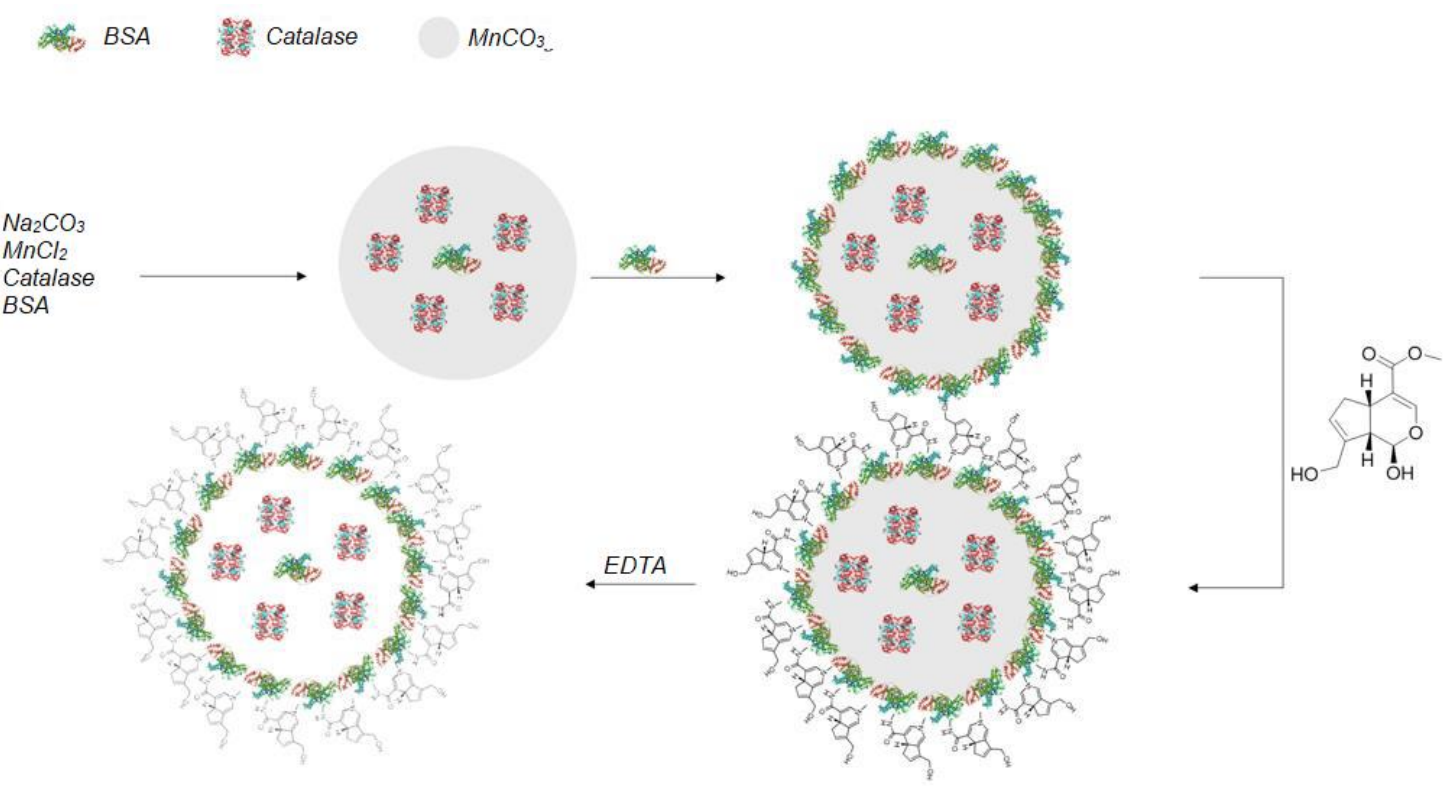

Figure 1: Synthesis of ACCs by co-precipitation of $\mathrm{MnCO}_{3}$ and catalase, followed by adsorption of BSA and cross-linking by genipin. The $\mathrm{MnCO}_{3}$ core is then dissolved using EDTA.

ACCs were created by a method first presented by XIONG et al. (Xiong et al. 2012, 2013, Li et al. 2017) and later modified by SCHAKOWSKI et al. (Schakowski et al. 2020). Cross-linking of the BSA molecules by genipin as described in previous works (Butler et al. 2003, Yoo et al. 
2011, Shahgholian et al. 2017, Schakowski et al. 2020) results in a stable shell of BSA around the core particle. Dissolution of $\mathrm{MnCO}_{3}$ from the core by EDTA finally leads to the release of formerly entrapped catalase to the inside of the created capsule.

Two aqueous solutions of $25 \mathrm{~mL}$, each containing $10 \mathrm{mg} \cdot \mathrm{mL}^{-1}$ Catalase, $1 \mathrm{mg} \cdot \mathrm{mL}^{-1}$ BSA and either $0.25 \mathrm{mM} \mathrm{Na}_{2} \mathrm{CO}_{3}$ or $0.25 \mathrm{mM} \mathrm{MnCl}_{2}$, respectively, were prepared. The $\mathrm{Na}_{2} \mathrm{CO}_{3}$ solution was placed in a $100 \mathrm{~mL}$ Erlenmeyer flask and the $\mathrm{MnCl}_{2}$ solution was added slowly under continuous vigorous stirring. After total merging of the two solutions, stirring was continued for two more minutes. Subsequently $125 \mathrm{mg}$ BSA was carefully added in portions and after total dissolution of the BSA, stirring was continued for five more minutes. The resulting suspension was equally split into two $50 \mathrm{~mL}$ reaction vessels and centrifuged at $1,000 \mathrm{~g}$ for two minutes. The supernatant was discarded and the residue was re-suspended in $40 \mathrm{~mL}$ of Ringer's solution each using shaking and ultrasonic bath. Centrifugation and washing were repeated two more times, before the residue was re-suspended in $40 \mathrm{~mL}$ of Milli-Q water each. The resulting suspensions were then merged into a $200 \mathrm{~mL}$ Erlenmeyer flask and under continuous stirring $20 \mathrm{~mL}$ of $940 \mu \mathrm{M}$ Genipin solution in Milli-Q water were added dropwise, resulting in a final concentration of $188 \mu \mathrm{M}$ Genipin. The aperture of the Erlenmeyer flask was then covered by aluminium foil and the suspension was stirred for 24 hours at room temperature.

The suspension was equally split into two new $50 \mathrm{~mL}$ reaction vessels and again centrifuged for two minutes at $1,000 \mathrm{~g}$ before the supernatants were discarded. $40 \mathrm{~mL}$ of $\mathrm{Na}_{2}$ EDTA solution of $\mathrm{pH} 7.4$ were added to each reaction vessel and the closed reaction vessels were shaken and kept in ultrasonic bath until all residue had fully dissolved. After centrifugation for two minutes at $1,500 \mathrm{~g}$ and discarding of the supernatants, this step was repeated once more. Emerging foam on the top of the supernatants was skimmed off and residues were suspended in $1 \mathrm{~mL}$ of Ringer's solution before being merged into a new suitable reaction vessel.

Prepared ACCs can be stored at $4{ }^{\circ} \mathrm{C}$ or $-20^{\circ} \mathrm{C}$ in Ringer's solution for more than six months maintaining a useful level of enzymatic activity.

This procedure has also been performed using $\mathrm{ZnCl}_{2}$ instead of $\mathrm{MnCl}_{2}$.

\subsection{Characterization}

\subsubsection{Transmission Electron Microscopy (TEM)}

Transmission Electron Microscopy was performed using a JEM 1400 Plus TEM (JEOL, Freising, Germany). 


\subsubsection{Respirometry assay}

Respirometry was performed on an Oroboros Oxygraph-2k Fluorespirometer (Oroboros Instruments, Innsbruck, Austria).

The chamber volume $V$ of the fluorespirometer was adjusted to $2 \mathrm{~mL}$ and $37^{\circ} \mathrm{C}$ and filled with $50 \mathrm{mM}$ sodium phosphate buffer or artificial serum, both of $\mathrm{pH}$ 7.4. After the oxygen background of the fluorespirometer had stabilized, $25 \mu \mathrm{L}$ of freshly prepared $120 \mathrm{mM} \mathrm{H}_{2} \mathrm{O}_{2}$ in $50 \mathrm{mM}$ sodium phosphate buffer of $\mathrm{pH} 7.4$ were injected into the chamber using a Hamilton syringe. After the oxygen flux had stabilized due to accelerated auto-degradation of $\mathrm{H}_{2} \mathrm{O}_{2}$ in artificial serum, $50 \mu \mathrm{L}$ of ACC-solution of different concentrations $c$ was injected into the chamber and oxygen flux was measured for five minutes.

The oxygen flux was corrected for the background flux due to auto-degradation and the average corrected oxygen flux $f$ was obtained by linear regression. The enzymatic activity $A$ was calculated as $\mathrm{A}=(2 \mathrm{f} \cdot \mathrm{V}) /(\mathrm{c} \cdot 50 \mu \mathrm{L})$, taking into account the ratio of produced $\mathrm{O}_{2}$ and degraded $\mathrm{H}_{2} \mathrm{O}_{2}$ in $2 \mathrm{H}_{2} \mathrm{O}_{2} \rightarrow \mathrm{O}_{2}+2 \mathrm{H}_{2} \mathrm{O}$.

The artificial serum (AS) was created by dissolving $298.2 \mathrm{mg} \mathrm{(4} \mathrm{mmol)} \mathrm{KCl,} 162.6 \mathrm{mg}$ (0.8 mmol) $\mathrm{MgCl}_{2} \cdot 6 \mathrm{H}_{2} \mathrm{O}, 266.4 \mathrm{mg}(2.4 \mathrm{mmol}) \mathrm{CaCl}_{2}, 2016.2 \mathrm{mg}$ (24 mmol) $\mathrm{NaHCO}_{3}$, $89.7 \mathrm{mg}$ (0.65 mmol) $\mathrm{NaH}_{2} \mathrm{PO}_{4} \cdot \mathrm{H}_{2} \mathrm{O}, 92.3 \mathrm{mg}$ (0.65 mmol) $\mathrm{Na}_{2} \mathrm{HPO}_{4}, 6665.1 \mathrm{mg}$ (114.05 mmol) $\mathrm{NaCl}$ and $50 \mathrm{~g}$ BSA in $1000 \mathrm{~mL}$ MilliQ water. The $\mathrm{pH}$ was adjusted to 7.4 at $37^{\circ} \mathrm{C}$ using $\mathrm{NaOH}$ and $\mathrm{HCl}$, each $\leq 1 \mathrm{M}$. AS was split into portions of $50 \mathrm{~mL}$ and stored at $-20{ }^{\circ} \mathrm{C}$. AS once thawed should be kept at $37^{\circ} \mathrm{C}$ and should be not be refrozen.

\subsubsection{Cell culture}

Cells were cultured in minimum essential medium (MEM) Eagle supplemented with $25 \mathrm{mM}$ sodium bicarbonate, 10\% FBS, $2 \mathrm{mM}$ L-glutamine, and 100 units $/ \mathrm{mL}$ penicillin $\mathrm{G}$ and $0.1 \mathrm{mg} / \mathrm{mL}$ streptomycin in $75 \mathrm{~cm}^{2}$ plastic flasks at $37{ }^{\circ} \mathrm{C}$ in a humidified atmosphere of $95 \%$ air and $5 \% \mathrm{CO}_{2}$. Subcultures were obtained by trypsinisation (0.05\% trypsin-EDTA). For experimental use, cells were transferred to 6-well plates.

\subsubsection{Cytotoxicity assays}

The standard cytotoxicity model of murine fibroblast-derived cell line L929 (American Type Culture Collection, NCTC clone 929 of strain L) was used for the experiments (Lomonosova et al. 1998). Cells were incubated in 6-well-plates under the described conditions over night. The medium was removed and $2 \mathrm{~mL}$ of $50 \mathrm{mM}$ sodium-phosphate buffer of $\mathrm{pH} 7.4$ and $50 \mu \mathrm{L}$ of trypan blue solution were added. 
For cytotoxicity of $\mathrm{H}_{2} \mathrm{O}_{2}, 50 \mu \mathrm{L}$ of freshly prepared $\mathrm{H}_{2} \mathrm{O}_{2}$-solution was added, so that final $\mathrm{H}_{2} \mathrm{O}_{2}$-concentrations in the wells were $0,1.25,2.5,5.0,7.5$ and $10 \mathrm{mM}$. Cells were counted by hand after $0,30,60,90,120,150$ and 180 minutes using an inverted microscope and the fraction of cells that had taken up trypan blue as a marker of loss of membrane integrity was calculated. For the duration of the experiment, cells were kept under described conditions.

For the cytotoxicity assay of ACCs, $100 \mu \mathrm{L}$ of ACC-suspension of different concentrations was added instead of $\mathrm{H}_{2} \mathrm{O}_{2}$. The period of observation was prolonged to 24 hours.

\subsubsection{Protection assay}

To determine the protective capacity of prepared ACCs, cells were incubated in 6-well-plates under described conditions. Again $50 \mu \mathrm{L}$ of trypan blue solution were added. Then $50 \mu \mathrm{L}$ of ACC-suspension were added with original concentrations of $0.001,0.005,0.010,0.100,0.250$ and 0.500 vol\%.

Results from $\mathrm{H}_{2} \mathrm{O}_{2}$ cytotoxicity assays served as control.

\section{Results and Discussion}

PHYSICAL PROPERTIES

Transmission electron microscopy was used to determine shape and size of the ACCs. Measuring the longest diameter of 452 single ACCs, prepared by using a $\mathrm{MnCO}_{3}$ template, yielded in a mean diameter of $1.245 \mu \mathrm{m}$ with a standard deviation of $0.272 \mu \mathrm{m}$. The overall range of diameters ranges from $0.433 \mu \mathrm{m}$ to $1.951 \mu \mathrm{m}$. As seen in figure 2, particles are shaped ellipsoid rather than round, whereas the core displays to have a peanut-like shape.

$\zeta$-potential was determined to be $-30.64 \mathrm{mV} \pm 7.76 \mathrm{mV}$. Each sample was measured three times and the overall mean and standard deviation were calculated. 


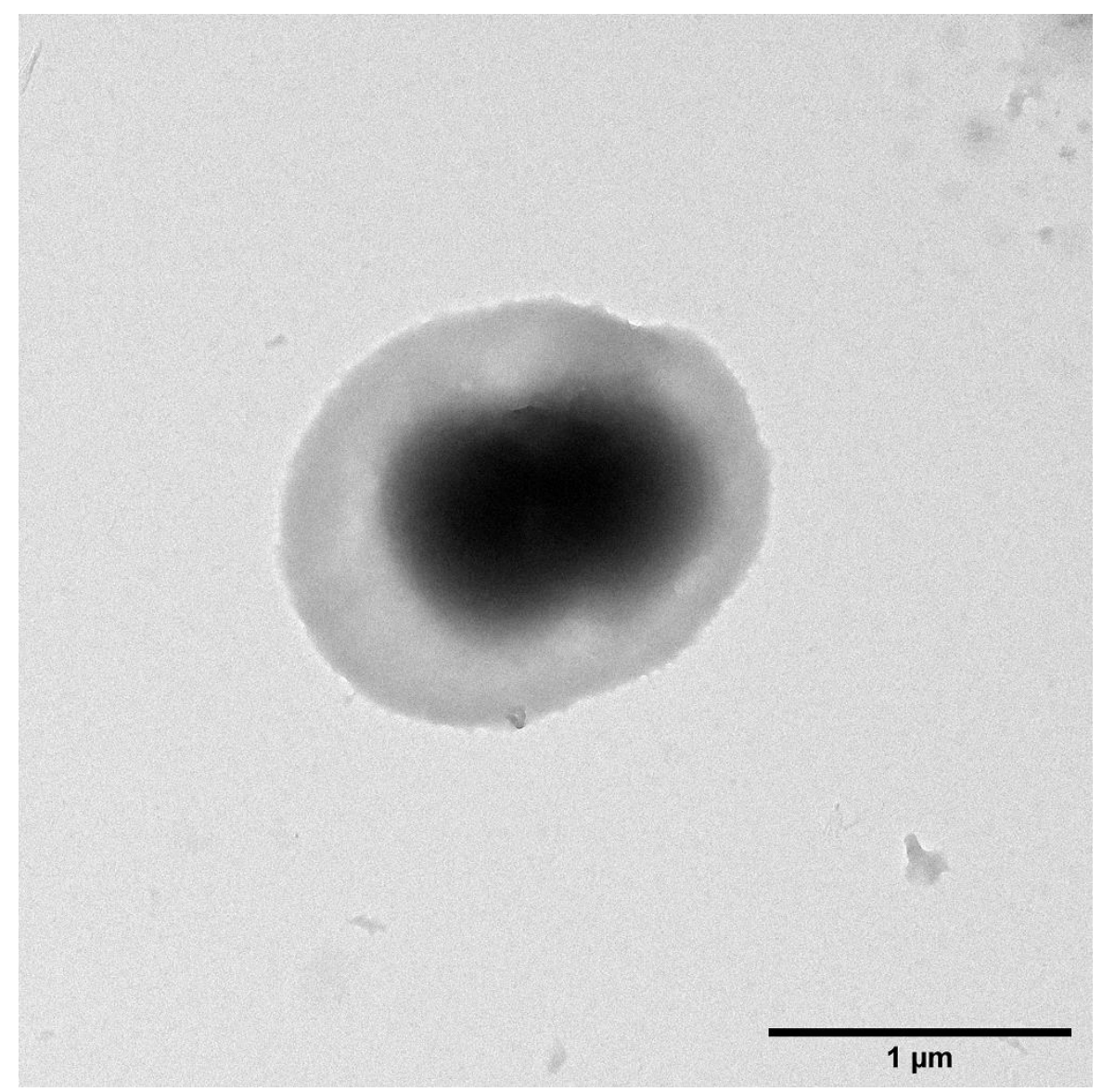

Figure 2: A solitary ACC from MnCO3 template pictured by TEM. Its longest diameter measures about $1.65 \mu \mathrm{m}$.

Using $\mathrm{ZnCO}_{3}$ as a template, solitary capsules observed were about $20 \%$ smaller, as seen in figure 3 (left), but have the great disadvantage of forming huge bulky adducts with large amount of inter-capsular cross-linking (right). Unfortunately, the changing of various parameters (e.g. kind of enzyme, albumin and cross-linking agent) failed in decreasing the amount of inter-capsular cross-linking to insignificant yields.

$\zeta$-potential was determined to be $-39.4 \mathrm{mV} \pm 2.94 \mathrm{mV}$. Each sample was measured three times and the overall mean and standard deviation were calculated. 


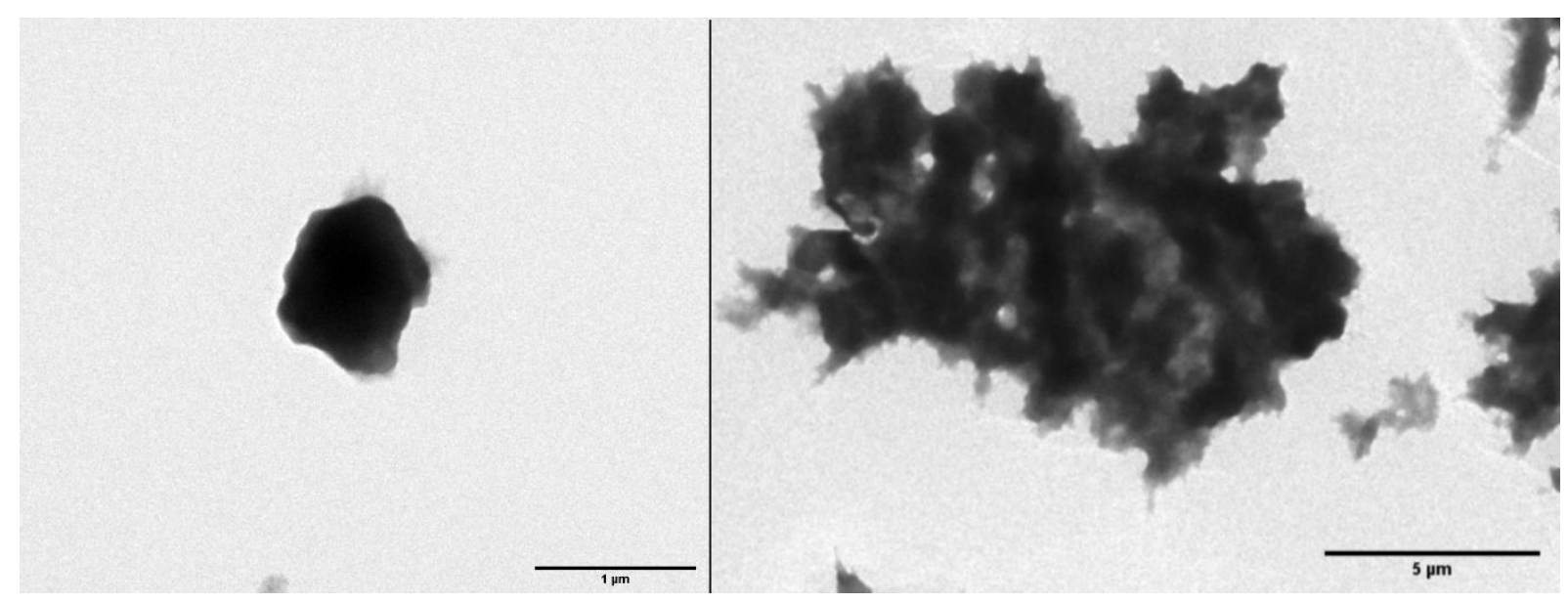

Figure 3: TEM images of a solitary ACC (left) and bulky adducts prepared from $\mathrm{ZnCO} 3$ templates. The longest diameter of the solitary ACC measures about $1 \mu \mathrm{m}$, while the adduct measures $13.2 \mu \mathrm{m}$.

\section{RESPIROMETRY}

Respirometry assays on general functionality were performed in $50 \mathrm{mM}$ sodium phosphate buffer at $\mathrm{pH} 7.4$ and $37^{\circ} \mathrm{C}(\mathrm{n}=4$ each). Interestingly, encapsulated catalase still maintained enzymatic activity. There was a clear dependence of enzymatic activity of ACCs from the volume concentration used for the assay, which is shown in figure 4 . This finding is allegeable by the high true activity of the ACCs, leading to experimental set-ups with $\mathrm{H}_{2} \mathrm{O}_{2}$ concentrations out of the ACCs substrate saturation. At higher peroxide concentrations any further observations were impossible due to the formation of oxygen bubbles.

Nonetheless, $\mathrm{ACCs}$ from $\mathrm{MnCO}_{3}$ templates displayed enzymatic activities higher than $1000 \mathrm{U} \cdot \mathrm{mL}^{-1} \cdot \mathrm{vol}^{-1}$ in concentrations of $0.001 \mathrm{vol} \%$ of the injected suspension.

Due to the smaller volume of ACCs from $\mathrm{ZnCO}_{3}$ templates, the amount of catalase used in preparation needed to be more than tripled to reach similar enzymatic activities per volume. At the maximum enzyme-binding capacity of the $\mathrm{ZnCO}_{3}$ templates, which equals 7.32-times the amount of enzyme used for $\mathrm{MnCO}_{3}$ templates, activities of about $2000 \mathrm{U} \cdot \mathrm{mL}^{-1} \cdot \mathrm{vol} \%{ }^{-1}$ were observed (data not shown). 


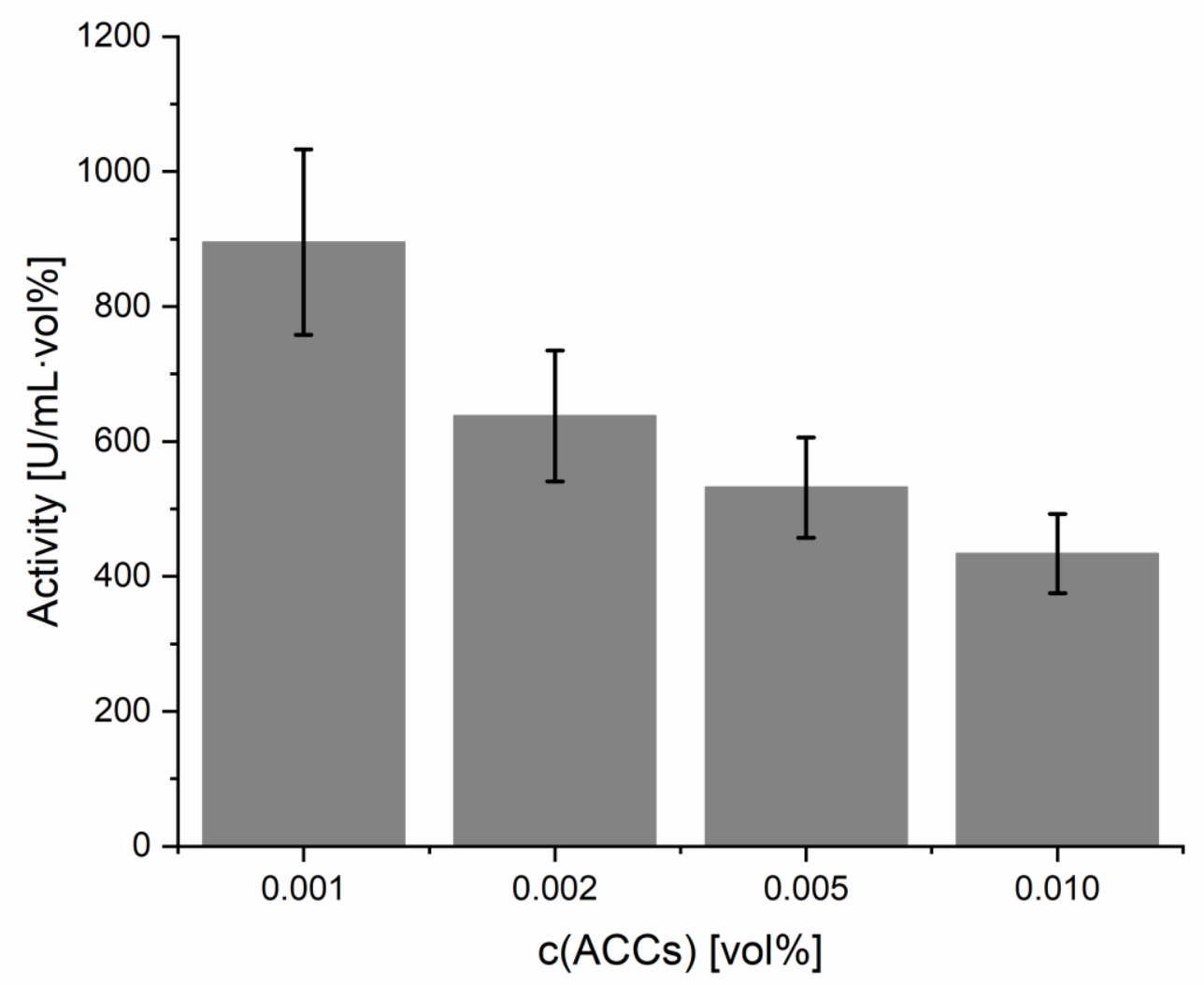

Figure 4: Determination of enzymatic activity of ACCs by respirometry. Mean values are represented by the grey bars. Black bars represent the standard deviation.

For better adaption of possible clinical scenarios and application, respirometry assays on storage conditions were performed in AS instead of phosphate buffer ( $n=4$ each). Furthermore, concentration of injected ACC suspension was decreased to 0.0002 vol\%.

ACCs were stored over night at $37{ }^{\circ} \mathrm{C}$, room temperature, $4{ }^{\circ} \mathrm{C}$ and $-20{ }^{\circ} \mathrm{C}$ and compared to the activity of freshly prepared ACCs of the same concentration. For ACCs stored at room temperature and at $37{ }^{\circ} \mathrm{C}$ any enzymatic activity of $\mathrm{H}_{2} \mathrm{O}_{2}$ degradation was lost beyond autodegradation, presumably accelerated by BSA present in AS. ACCs stored at $4{ }^{\circ} \mathrm{C}$ still displayed a mean activity of $45.6 \%$ with a standard deviation of $4.9 \%$ compared to freshly prepared ACCs. ACCs stored at $-20{ }^{\circ} \mathrm{C}$ even maintained an activity of $67.8 \%$ with a standard deviation of $1.5 \%$ compared to freshly prepared ACCs. It is therefore tentatively suggested to storage ACCs at $-20{ }^{\circ} \mathrm{C}$ after preparation. After thawing ACCs should be applied without further delay. If delay is inevitable, thawed ACCs should be stored at $4{ }^{\circ} \mathrm{C}$. The results are depicted in figure 5 . 


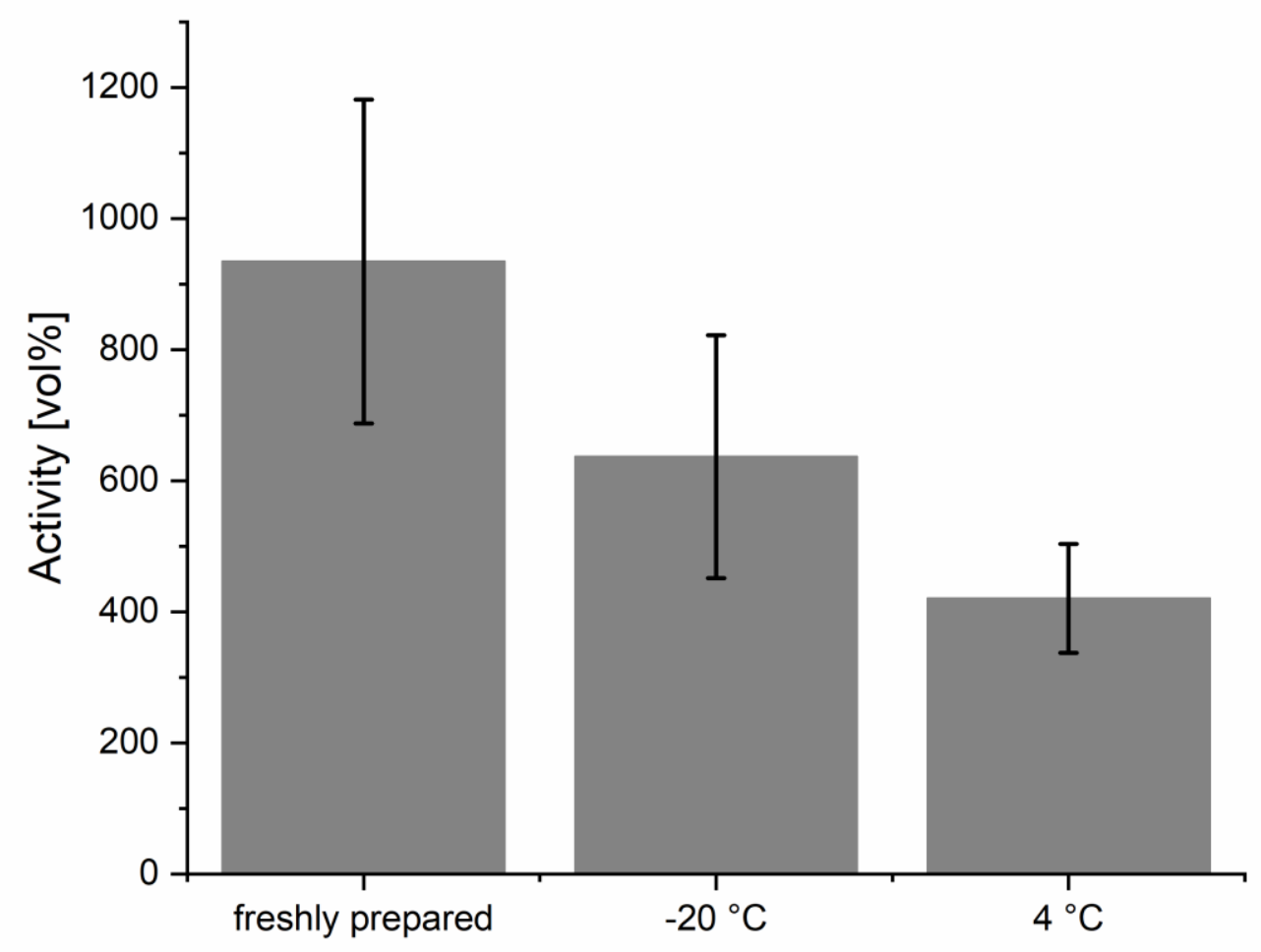

Figure 5: Dependance of ACC activity from storage temperature. Mean values are represented by the grey bars. Black bars represent the standard deviation.

\section{Cell culture}

In the cytotoxicity assay $(n=3)$, ACCs seemed to be harmless to the L929 cells since uptake of trypan blue did not take place within the observation period of $3 \mathrm{~h}$. Therefore, the observation period was prolonged to $24 \mathrm{~h}$, but again any uptake of trypan blue by L929 cells did not occur.

Protection assays were only performed with ACCs from $\mathrm{MnCO}_{3}$ templates under described conditions (vide supra) with $50 \mathrm{mM}$ sodium phosphate buffer at $\mathrm{pH} 7.4$ as solvent $(\mathrm{n}=3)$. In line with previous experiments (vide supra), ACC concentrations $\geq 0.1 \mathrm{vol} \%$ did not evoke any trypan blue uptake in L929 cells, but were evident for ACC concentrations up to 0.05 vol\% as shown in figures 6 and 7.

For final $\mathrm{H}_{2} \mathrm{O}_{2}$ concentrations $<2.5 \mathrm{mM}$ a low-dose ACCs $(0.001 \mathrm{vol} \%)$ application failed in protecting L929 cells $(\mathrm{p}=0.34)$, whereas a medium-dose ACCs $(0.01$ vol\%) already displayed a protective effect $(\mathrm{p}=0.08)$ as seen in figure 6 . 


\section{$1.25 \mathrm{mM} \mathrm{H}_{2} \mathrm{O}_{2}$}

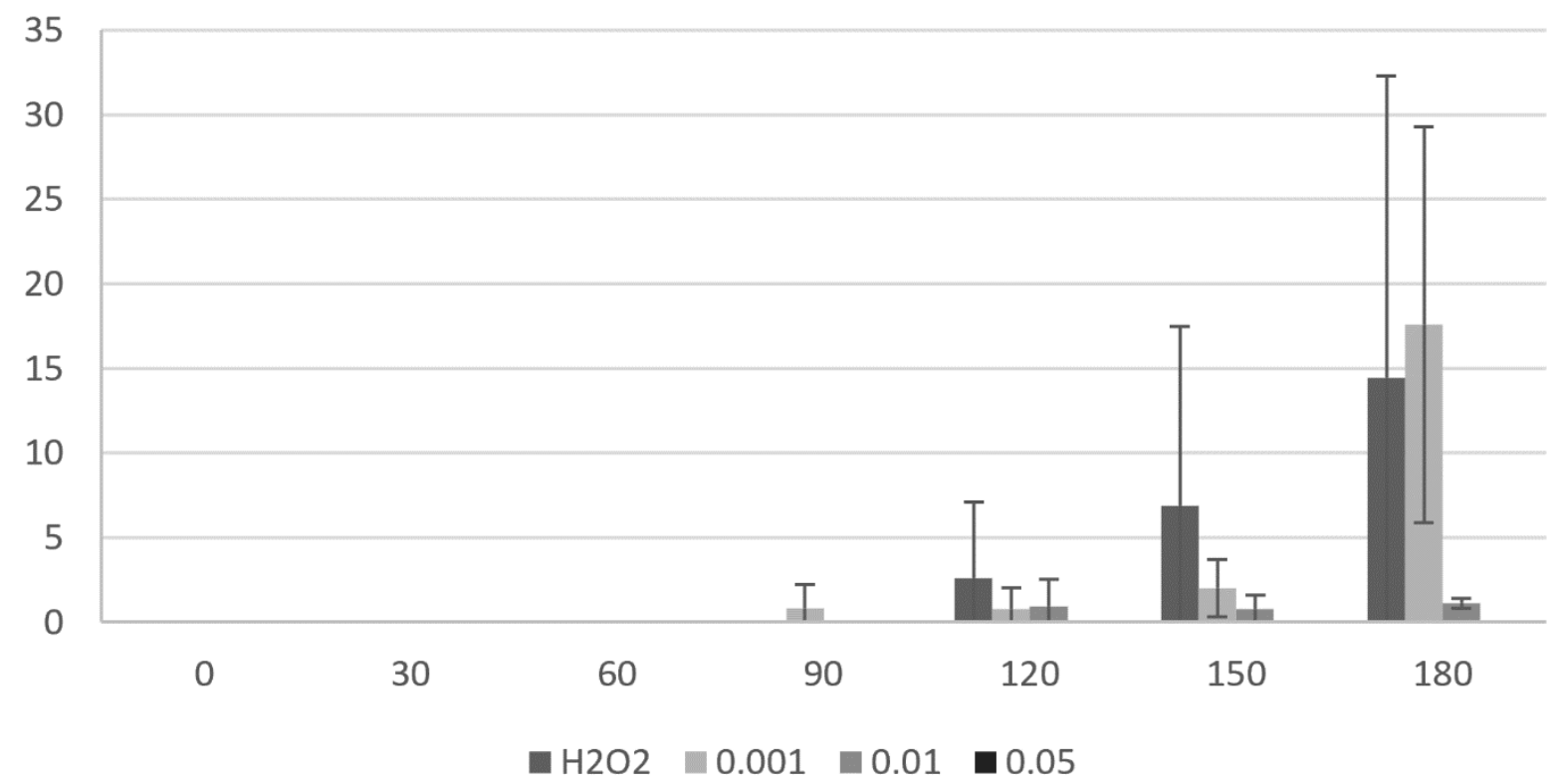

Figure 6: Protection assay performed using low concentrations of $\mathrm{H} 2 \mathrm{O} 2$. No protective effect can be observed using low-dose ACCs. The grey bars represent the mean values, while standard deviation is shown by the black bars.

Interestingly, for $\mathrm{H}_{2} \mathrm{O}_{2}$ concentrations $\geq 2.5 \mathrm{mM}$ both low-dose and medium-dose ACCs seemed to have an adverse effect, leading to increased cell damage ( $\mathrm{p}<0.008)$. High-dose ACCs (0.05 vol\%) presented to have significant protective effect for all chosen $\mathrm{H}_{2} \mathrm{O}_{2}$ concentrations. For $\mathrm{H}_{2} \mathrm{O}_{2}$ concentrations $<7.5 \mathrm{mM}$ any trypan blue uptake by L929 cells was prevented by applying ACC concentration of $0.05 \mathrm{vol} \%$ or higher. If $\mathrm{H}_{2} \mathrm{O}_{2}$ concentration was $\geq 7.5 \mathrm{mM}$, only high-dose ACCs displayed significant protective effects ( $\mathrm{p}<0.005$ ). Figure 7 displays the depicted findings. 


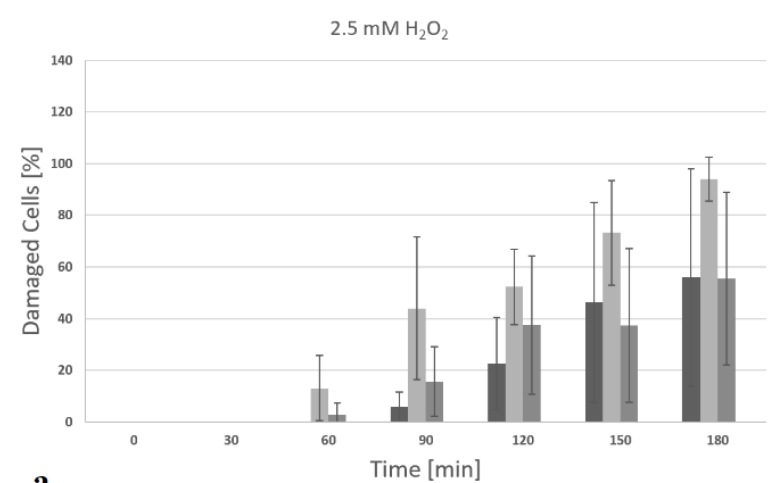

a

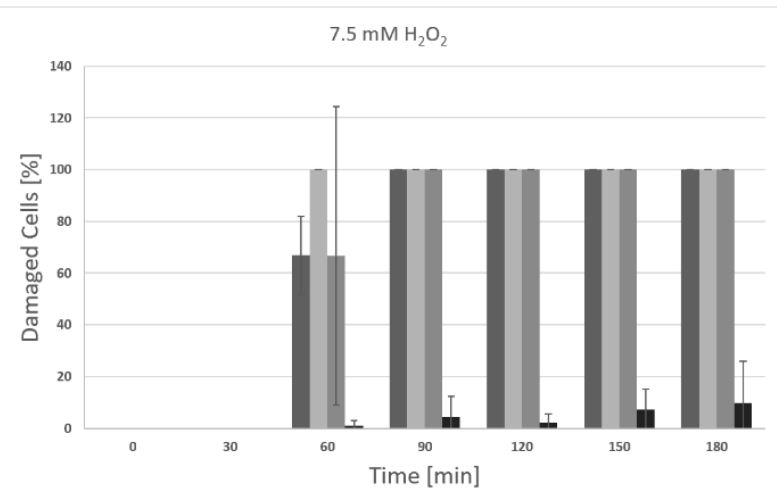

c

- $\mathrm{H} 2 \mathrm{O} 2$

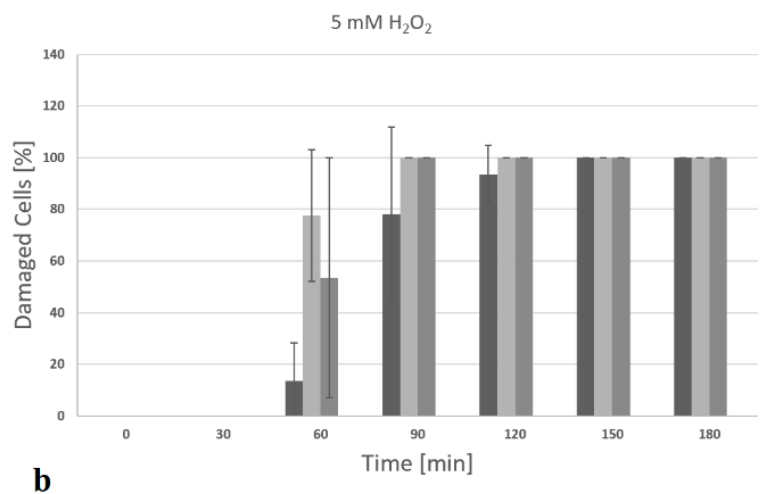

b

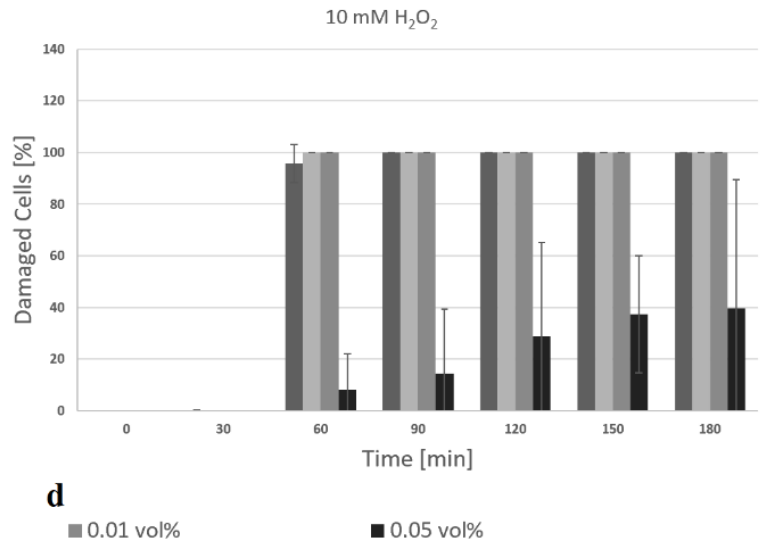

Figure 7: Results of the protection assay using higher peroxide concentrations. The grey bars represent the mean values, while standard deviation is shown by the black bars.

\section{Conclusion}

Catalase capsules prepared by the developed method remain highly enzymatically active and decreased peroxide induced cell damage up to $90 \%$ at higher concentrations, if dosed correctly. A too low dosage should be avoided because this might result in driving harmful effects. In further assays, co-encapsulation of catalase and other intracellular RBC enzymes, e.g. superoxide dismutase or carbonic anhydrase, could be the next step in developing tools for artificial oxygen carriers. In principle, the presented method can be applied for both perfluorocarbon-based oxygen carriers and hemoglobine-based ones, but, of course, a coencapsulation of enzymes occurring in erythrocytes together with hemoglobin might be a mandatory formulation in the near future.

\section{Acknowledgements}

The authors thankfully express their gratitude to Mr. Bernd Walkenfort from the Electron Microscopy Unit of the Imaging Centre Essen (IMCES) for the performance of TEM imaging.

\section{Disclosure statement}

The authors report no conflict of interests. 


\section{Data availability statement}

All data used in this work is publicly available at https://www.doi.org/10.7303/syn23519345

\section{Funding statement}

No external funding was provided for this work.

\section{References}

Bauer, J., Zähres, M., Zellermann, A., Kirsch, M., Petrat, F., de Groot, H., and Mayer, C., 2010. Perfluorocarbon-filled poly(lactide-co-gylcolide) nano- and microcapsules as artificial oxygen carriers for blood substitutes: a physico-chemical assessment. Journal of Microencapsulation, 27 (2), 122-132.

Butler, M.F., Ng, Y., and Pudney, P.D.A., 2003. Mechanism and kinetics of the crosslinking reaction between biopolymers containing primary amine groups and genipin. Journal of Polymer Science Part A: Polymer Chemistry, 41 (24), 3941-3953.

Chang, T.M.S. and Yu, W.-P., 1995. Biodegradable polymer membrane containing hemoglobin for blood substitute.

Chung, K.-W., Basavaraju, S. V, Mu, Y., van Santen, K.L., Haass, K.A., Henry, R., Berger, J., and Kuehnert, M.J., 2016. Declining blood collection and utilization in the United States. Transfusion, 56 (9), 2184-92.

Ellingson, K.D., Sapiano, M.R.P., Haass, K.A., Savinkina, A.A., Baker, M.L., Chung, K.-W., Henry, R.A., Berger, J.J., Kuehnert, M.J., and Basavaraju, S. V, 2017. Continued decline in blood collection and transfusion in the United States-2015. Transfusion, 57 Suppl 2 (Suppl 2), 1588-1598.

Heard, W.N., 1913. The reaction between metallic salts and the soluble carbonates and its bearing upon the precipitation of protein. The Journal of Physiology, 46 (2), 104-128.

Johnson, K.S., 1982. Solubility of rhodochrosite (MnCO3) in water and seawater. Geochimica et Cosmochimica Acta, 46 (10), 1805-1809.

Li, H., Xiong, Y., Zhang, Y., Tong, W., Georgieva, R., Bäumler, H., and Gao, C., 2017. PhotoDecomposable Sub-Micrometer Albumin Particles Cross-Linked by ortho -Nitrobenzyl Derivatives. Macromolecular Chemistry and Physics, 1700413.

Lomonosova, E.E., Kirsch, M., and de Groot, H., 1998. Calcium vs. iron-mediated processes in hydrogen peroxide toxicity to 1929 cells: effects of glucose. Free Radical Biology and Medicine, 25 (4-5), 493-503. 
Müller, M.M., Geisen, C., Zacharowski, K., Tonn, T., and Seifried, E., 2015. Transfusion of Packed Red Cells. Deutsches Aerzteblatt Online.

Schakowski, K.M., Linders, J., Ferenz, K.B., and Kirsch, M., 2020. Synthesis and characterisation of aqueous haemoglobin-based microcapsules coated by genipin-crosslinked albumin. Journal of Microencapsulation, 37 (3), 193-204.

Shahgholian, N., Rajabzadeh, G., and Malaekeh-Nikouei, B., 2017. Preparation and evaluation of BSA-based hydrosol nanoparticles cross-linked with genipin for oral administration of poorly water-soluble curcumin. International Journal of Biological Macromolecules, 104 (Pt A), 788-798.

Simoni, J., Simoni, G., Hartsell, A., and Feola, M., 1997. An Improved Blood Substitute: In Vivo Evaluation. Artificial Organ Research and Development, 43 (5), 714-725.

Turrens, J.F., Crapo, J.D., and Freeman, B.A., 1984. Protection against Oxygen Toxicity by Intravenous Injection of Liposome-entrapped Catalase and Superoxide Dismutase. The Journal of Clinical Investigation, 73 (1), 87-95.

Wrobeln, A., Schlüter, K.D., Linders, J., Zähres, M., Mayer, C., Kirsch, M., and Ferenz, K.B., 2017. Functionality of albumin-derived perfluorocarbon-based artificial oxygen carriers in the Langendorff-heart. Artificial Cells, Nanomedicine, and Biotechnology, 45 (4), $723-$ 730.

Xiong, Y., Liu, Z.Z., Georgieva, R., Smuda, K., Steffen, A., Sendeski, M., Voigt, A., Patzak, A., and Bäumler, H., 2013. Nonvasoconstrictive Hemoglobin Particles as Oxygen Carriers. ACS Nano, 7 (9), 7454-7461.

Xiong, Y., Steffen, A., Andreas, K., Müller, S., Sternberg, N., Georgieva, R., and Bäumler, H., 2012. Hemoglobin-Based Oxygen Carrier Microparticles: Synthesis, Properties, and In Vitro and In Vivo Investigations. Biomacromolecules, 13 (10), 3292-3300.

Yoo, J.S., Kim, Y.J., Kim, S.H., and Choi, S.H., 2011. Study on Genipin: A New Alternative Natural Crosslinking Agent for Fixing Heterograft Tissue. The Korean Journal of Thoracic and Cardiovascular Surgery, 44 (3), 197-207. 